\title{
Paul Flechsig's System of Myelogenetic Cortical Localization in the Light of Recent Research in Neuroanatomy and Neurophysiology Part I
}

\author{
ALFRED MEYER
}

SUMMARY: In the first part of the paper supplementary information on Flechsig's personality and his attitude to work is given which had not been sufficiently appreciated in English biographical notices. This is followed by translated excerpts from "Gehirn and Seele", published in 1896, in which Flechsig introduced his myelogenetic localization of the cerebral cortex.

The second part is mainly a review of

RÉSUMÉ: Dans la première partie de ce travail, nous donnons des informations supplémentaires sur la personnalité de Flechsig et sur son attitude envers le travail, faits non suffisamment mentionnés dans les notes biographiques en langue anglaise. Nous présentons ensuite une traduction d'extraits de son oeuvre " $\mathrm{Ge}$ hirn und Seele". publiée en 1896, dans laquelle Flechsig introduit son travail de la localisation myélogénétique du cortex recent advances in neuroanatomical and neurophysiological research within those cortical regions in which Flechsig had been interested. A comparison between recent advances and Flechsig's work demonstrates that Flechsig had definitive ideas on the solution of some of the outstanding problems but had been unable to resolve these with the techniques available at his time.

cérébral.

La deuxième partie du travail consiste surtout en une revue des progrès récents de la recherche neuroanatomique et neurophysiologique dans les régions corticales d'intérêt pour Flechsig. Une comparaison des données de Flechsig et des progrès récents montre que l'auteur avait des idées claires sur la solution de certains problèmes, mais qu'il n'avait pu les résoudre avec les techniques à sa disposition.
Professor Meyer was formerly at the Department of Neuropathology, Institute of Psychiatry, London.

PART Il of this paper will appear in the May Issue and will include all the references to Parts 1 \& II.

Reprints will be available after Part Il has been published from Professor Alfred Meyer, 38 Wood Lane, London N6 5UB, U.K.

\section{INTRODUCTION}

There is no need for a new biography of the life and work of Paul Flechsig. In the introduction to his last book of 1927 (two years before his death, almost exactly a half-century ago), he included an autobiography. In addition, there are three brief, but adequately informative appreciations, two in German by Schroder (1930) and Pfeifer (1930) and one in English by Haymaker (1970), while Clarke and O'Malley (1968) have provided translated extracts of the main aspects of Flechsig's work. Schröder was one of Flechsig's successors to the chair of Neurology and Psychiatry at Leipsig. Arwed Pfeifer worked with Flechsig from 1915 until Flechsig's retirement in 1931 and he remained in close contact with him until Flechsig's death. His contribution is, therefore, of especial importance for our understanding of the man and his work.

\section{SOME SUPPLEMENTARY}

\section{BIOGRAPHICAL REMARKS}

Flechsig came from an old Saxonian family. He was born at Zwickau in that part of Saxonia known as the Voigtland. Pfeifer tells us that Flechsig often narrated that in old church books the name of his ancestors was "Flächsing" which referred to their flaxen hair. Flechsig himself had flaxen hair. He demonstrated many of the Voigtlanders' characteristics: he was, according to Haymaker, of a big, broad build, a strong and strong-willed individual with a tendency to be abrupt and dogmatic - characteristics which explain that he made a number of enemies and his work was often underestimated, particularly in later years. There are other reasons why he was inclined to make enemies: Pfeifer mentions his cyclothymic temperament, accompanied by a predominantly pyknic physique. Only those close to him knew of the cycloid phases; at times he was 
indefatigable and irresistibly stimulating in his work with his associates and students; not only Pfeifer, but also a distinguished research worker such as Held regarded these periods as the most enjoyable time of their lives. There were, however, other periods, often lasting for a long time, when he was depressed, irritable, overbearing, unjust and tyrannical, often lethargic, isolating himself and incapable of any work: those who knew him only in such periods (such as, perhaps, Oscar Vogt), had good reason to be critical of his personality. Pfeifer mentioned also that he was worried by the long invaliding illness of his wife and her eventual death. Later, at the age of 75 , he remarried and his second wife made him happy until his death at the age of 82 . During this final period he enjoyed social life, went to concerts, and liked country walks. He remained indefatigable in his work and "a passionate worker" (as he said of himself), stimulating all those around him almost to the time of his death.

\section{WORK ON LOWER CENTERS}

Flechsig belonged to the relatively small group of doggedly single-minded scientists who, once they have chosen a suitable subject, stick to it throughout their professional life. He came to Leipzig as a student and stayed throughout his career (with short interruptions) and eventually died there.

While working with Ernst Wagner, the pathologist, and sectioning the brains of newborn infants he noticed white streaks within the white matter which indicated early myelinating tracts. As early as 1872 he demonstrated the "myelogenetic method" which earned him praise from Helmholtz and Ludwig and which, in the words of Schröer (1930), signified the "great thrust in his research." He became head of the histological department in Carl Ludwig's laboratory in 1873 and began systematically to use the new method, beginning with the spinal cord; this research was published in his book (1876) "Die Leitungsbahnen im Gehirn und Rückenmark" (tracts of conduction in brain and spinal cord).

The two outstanding results were his discovery of the dorsal spinocerebellar tract (which bears his name) and the detailed description of the pyramidal tract throughout its course up to the internal capsule. He was not sure, however, (p. 345) whether the tract ended in one of the basal ganglia or proceeded to the central cortical convolutions; not before 1877 did he become convinced that the tract could be traced into the central cortex. By this time Gudden (1872) and Charcot (1876) had demonstrated secondary degeneration of the tract following lesions in the central convolutions. However, at that time nobody had traced the pyramidal tract as completely as Flechsig had done with the help of one method. He elaborated this success in 1881 and 1883 by analysing the position of both descending and ascending tracts within the internal capsule in front and behind its knee: this has been universally accepted.

In 1878 Flechsig, strongly supported by Ludwig and the distinguished physician Kussmaul, was offered the chair of Psychiatry and Neurology at a new mental hospital which was to be built at Leipzig. It is yet another sign of his seriousness of purpose that he spent the four years until the opening of his hospital in improving his psychiatric knowledge by visits to distinguished psychiatric centers in Germany and abroad, including Charcot's clinic at the Salpêtrière. Pfeifer tells us this was not an easy time for Flechsig who shortly after his appointment in 1878 had a period of serious depression with insomnia. It took him an appreciable time to learn to sleep again and to benefit from the self-imposed years of psychiatric apprenticeship. When the new hospital was at last opened in 1882, he was soon joined by a large number of disciples from many countries including Beevor, Darkschewitz, Tschirch, Oscar Vogt, Martinotti, Bechterew, Donaldson, Schütz, Held and at a later date Pfeifer — all men who subsequently acquired the highest reputations.

In 1885 Bechterew, who was inspired by him, found that the inferior corpus quadrigenium was connected through the lateral lemniscus with the superior olive and the trapezoid body, and thus, with the eighth cranial nerve; he used the term "lateral" instead of "inferior" lemniscus of previous authors. He also discovered its ganglion name by him "nucleus of the lateral lemniscus." Bechterew's findings were confirmed by Flechsig in 1886. A decade later (in 1896) Flechsig was able of identify - again with the myelogenetic method - the first transverse (Heschl) convolution as the cortical auditory center and described what is known as Flechsig's loop of the visual radiation within the temporal lobe. However, the greatest significance of "Gehirn und Seele" (1896) is that it contains the first full publication (a preliminary account of his "Rector's Oration" had been published in 1894) of his myelogenetic research on cortical localization. This publication brought the first twenty years of unusual single-minded research which began in 1876 with his "Leitungsbahnen" to a certain conclusion.

As I have mentioned, two publications by Flechsig on his architectonic system have already been translated into English: the first was published in 1901; a translated excerpt has been provided by Clarke and O'Malley $(1968$, p. 545) together with excerpts from Flechsig's brief account of 1900 , and from his book of 1920 . The second (reproduced by von Bonin, 1960, p. 181) was taken from a lecture given by Flechsig to the International Psychological Congress at Rome in $1905^{\mathrm{a}}$.

With their fig. 134 (dated 1904) Clarke and O'Malley have also provided an illustration (which they believe to be his best) of Flechsig's intermediate and terminal zones. I have not yet been able to see the original, but in his paper of $1905^{b}$ (with the same title) Flechsig produced two figures (figs. 1 and 2 of the present paper) which are identical both in quality and myelogenetic detail, with those of Clarke and O'Malley. However, they do not represent the final results of Flechsig's research: in 1904 and 1905 the number of identified fields had been 36 , by 1920 this had grown to 45 (Flechsig 1920, figs. 1 and 2 [ 3 and 4 of the present paper]). Moreover, in the publications of 1904 and 1905 , field 36 was placed within the inferotemporal region, while in 1920 , field 45 is found in the second frontal convolution. As we shall see later, it was the illustrations of 1920 which Yakovlev (1962) selected for his "morphogenetic" research.

To my knowledge no translations exist of Flechsig's "Gehirn und Seele" (or parts of it). This is regrettable because it was this publication which caused the great stir. In 1896, Flechsig distinguished four cortical "sensory spheres" and three "association-zones". The former are 1) Munk's "Körperfühlsphäre" (best translated as "somatic sensory sphere"); its posterior limit is formed by the postcentral sulcus, while orally it extends to include the cortical origin of Arnold's fronto-pontine bundle. 2) The "olfactory sphere" within the uncinate gyrus at its 
anterior end near the amygdaloid nucleus. 3) The "visual sphere" and 4) the "auditory sphere" which Flechsig himself had discovered mainly within the first transverse (Heschl) convolution.

In the following pages I shall provide translated excerpts of relevant parts of Flechsig's association-centers which he discussed in pages 78 to 85 of "Gehirn und Seele". He distinguished three such centers - an anterior, middle and posterior one. The middle, comprising mainly the insular cortex, was omitted in subsequent publications - as we shall see, for reasons which he gave in 1896 .

\section{TRANSLATED EXCERPTS FROM "GEHIRN UND SEELE" (1896) pp. 78-85.}

(All italics and ordinary brackets are those of Flechsig. Square brackets contain remarks by the present author)

\section{"II. ASSOCIATION CENTRES"}

In the first edition of this lecture I had distinguished four association centers because. I did not appreciate enough how much the temporal and parietal centers belong to one another on the convexity. It seems to be more expedient to regard them as a functional unit. As will become clear in the following considerations, this change will also improve the outline of the total plan of the cerebrum.

\section{The posterior large association center:}

This very large region which ... covers almost half of the cerebrum ... comprises the praecuneus, all the parietal convolutions, parts of the lingual gyrus, the fusiform ('Spindelwindung') convolution, the second and third temporal convolution together with the temporal pole and the anterior parts of all three occipital convolutions on the convexity...

This whole complex of regions has a common architecture of the cortex, i.e., the five layer type of Meynert; I do not, however, attach especial significance to five layers, I only wanted to make clear that the cortex was of the type which Meynert had described. In his 5 th layer beneath the granular layer, large pyramidal cells were rare. In his third layer I found that the size of the pyramidal cells varied within different regions.

Different convolutions within the aforesaid large region do not receive myelinated fibers at the same time. The occipital parts receive them earlier than the others, and at the border between the second temporal and second occipital gyrus, there is a place

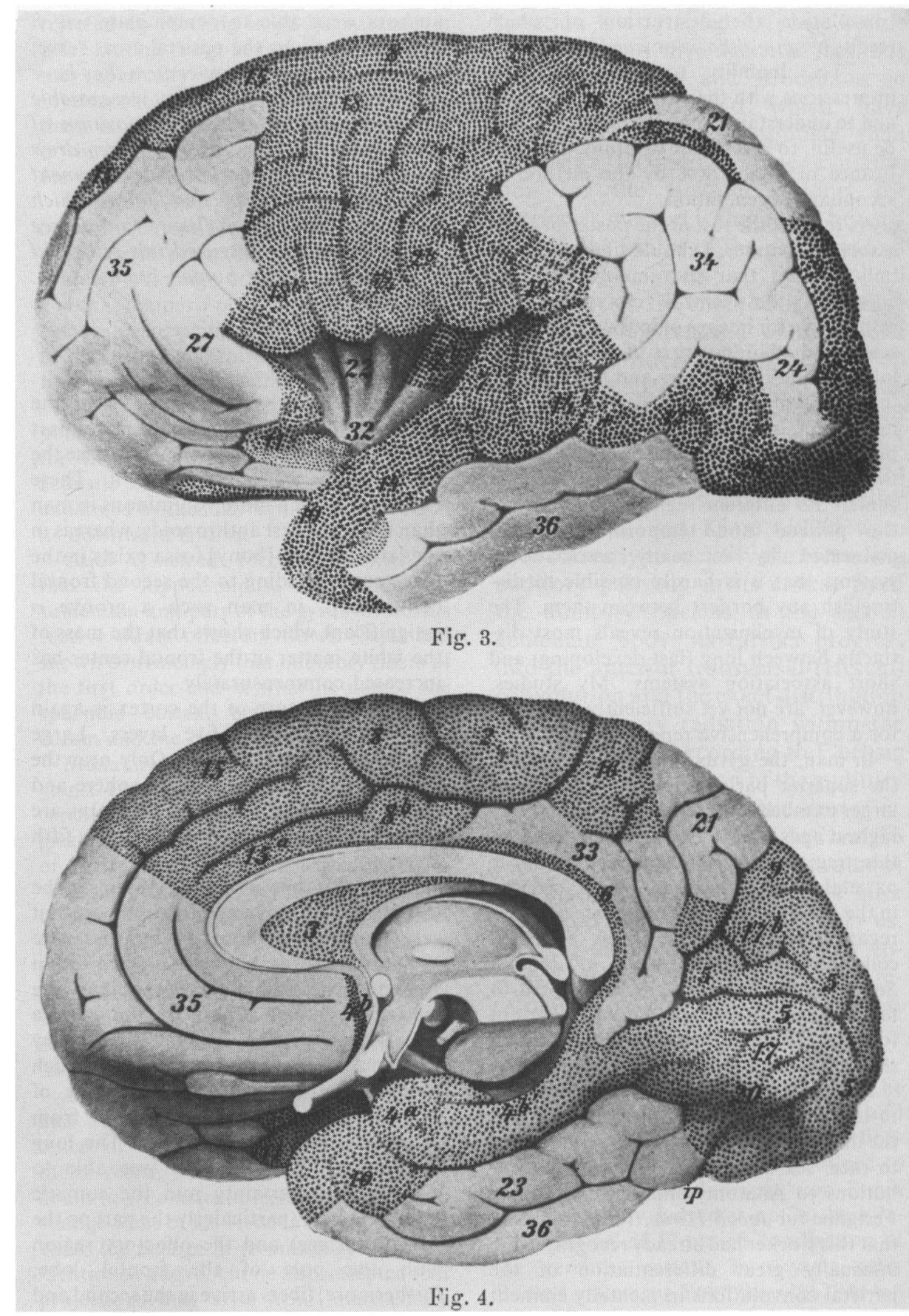

Figures 1 and 2 - (reproduced from figs. 3 and 4 of the Flechsig, 1905; by courtesy of the Librarian, Royal Society of Medicine, London): showing the myelogenetic fields numbered according to the time of myelination on both lateral and medial cortical surfaces. The lightly coloured fields correspond to Flechsig's terminal zones, as the high numbers indicate. Further explanation in text.

which differs from the other regions because of its development and its wealth of myelinated fibers .... I particularly stress this point because this region, partially at least, is undoubtedly identical with the gurus angularis of monkers. Since
Ferrier believed this to be part of the [visual] sensory sphere, an early development would be of especial interest. In view of my own anatomical findings, however, I am unable to accept Ferrier's opinion; I rather believe it is the important 
convolution the destruction of which results in optic aphasia or word blindness. . i.e., inability to associate visual impressions with the corresponding words and to understand written words .... It will be useful, to investigate carefully the significance of region XX by the method of secondary degeneration.

As regards the rest of the posterior large association-center, I should like to remark only briefly, that presumably the part adjoining the central convolution is responsible for images of muscle and tactile sense, the adjoining part of the temporal lobe for auditory images and finally those in the occipital lobe for visual images. I do not expect, however, that the main contact between all these disparate centers will be found exactly in the middle of the large center. Its different regions (especially in the parietal and temporal lobe) are connected by so many associational systems that it is hardly possible to distinguish any borders between them. The study of myelinization reveals most distinctly between long (last developing) and short association systems. My studies, however, are not yet sufficiently advanced for a comprehensive report.

In man, the gyrus supramarginalis and the superior parietal convolution show a larger number of secondary gyri than in the highest apes, and the great development of this region which corresponds to the parietal bump, is especially characteristic in the brains of eminent persons..... With regard to the findings of my esteemed colleague $H$ is in the skull of Johann Sebastian Bach, one might be tempted to localize here an essential factor important for musical talent, because the cast of this skull showed an enormous development ...

In an essay by Rüdinger (A contribution to the anatomy of the Simian fissure and the interparietal sulcus in man with respect to race, sex and individuality, in: Contributions to Anatomy and Embryology Festgabe für Jacob Henle, 1882) it is seen, that this worker had already recognized the unusually great differentiation of the parietal convolutions in mentally eminent men and their much inferior development in less intelligent Germans as well as in lower races. Rüdinger provides illustrations of the brains of, among others, Justus von Liebig, Lassaulx and the physiologist Döllinger: he also mentions that Kupfer had demonstrated the unusual development of the parietal region when describing the skull of Kant; the brains of Gauss, Dirichlet and others in the illustrations of Rudolf Wagner show the same. Hence the parietal convolutions are of outstanding importance, not only for musicians (e.g. Bach .... Beethoven), but also for great scientists. However, none of the earlier authors were able to contemplate which especial functions the parietal areas serve; that they are association-centers they have completely ignored since they were unable to appreciate the anatomical position of these parts. Incidentally, Rüdinger drew attention to the remarkable development of the superior parietal convolutions which shortened the "Simian fissure to a degree that more or less obscured this pithecoid characteristic in the human brain." . . . . (pp. 78-81)

\section{The anterior association center}

This is formed by the anterior half of the first frontal convolution and the major part of the second convolution. At the base the gyrus rectus also belongs to it. These regions are much more voluminous in man than in the highest anthropoids; whereas in the latter a deep [bony] fossa exists in the place corresponding to the second frontal convolution, in man such a groove is insignificant which shows that the mass of the white matter in the frontal center has increased commensurately.

The architecture of the cortex is again the regular one of five layers. Large pyramidal cells are absent. Only near the border of the somatic sensory sphere and medially down to the gyrus fornicatus are larger cells found, here also in the fifth layer.

As regards the association systems of the frontal system, my investigations are not yet complete. Without doubt, these are extraordinarily developed, since projection systems form only a minor part of the white matter. Although fibers of the corona radiata reach almost the frontal pole, they bend in a pointed angle caudalward (which is important to the symptomatology of frontal lesions, to conclusions from secondary degenerations, etc.). The long association fibers which $I$ was able to identify with certainty join the somatic sensory sphere (particularly the part on the medial surface) and the olfactory region with the pole of the frontal lobe; furthermore, fibers arrive in the second and first convolution from the third frontal convolution... I was not yet able to ascertain whether the auditory and visual spheres are connected with the frontal association center. It looks as if in addition to the cingulum .... there exist fiber tracts which connect the visual area as well as the parietal association complex with the frontal association-center.

Association fibers .... also run from the region of the auditory cortex towards the frontal association-center. Although so far I do not have any definitive proof, it is possible that the frontal association system has connexions with all sensory systems; but so far only connexions with the olfactory and somatic sensory sphere have been definitely established. Thus it is tempting to propose that, in particular, the images of many pleasurable and displeasurable sensations, instinctual urges, movements and actions - i.e., the essential components of the consciousness of the personal self and the most important regulations of our actions - depend on the frontal association system. These are also of decisive importance for the empirical judgement of our own working capacity and of what to aim at and what to avoid; they may help us to understand that a diseased frontal lobe first results in extravagant over- or underestimation of our own person, and later in total lack of interest, self-oblivion and defective judgement .... (pp. 81-82)

A comparison between the three association centers reveals a remarkable difference in so far as the insular cortex has only few callosal connexions, whereas both the anterior and posterior association-centers are distinguished by unusually numerous callosal fibers. These two centers therefore have a very intimate relationship with both hemispheres whereas each insula is mainly of importance to ipsolateral regions. Hence the insula is of a more local significance; for mental life it is rather the two other centers which should be considered ....

The number of association fibers which connect the anterior and posterior great association-centers appear to be rather small: one may therefore surmise that possibly there are other connexions. Such connexions could be found only in the somatic sensory sphere which is interpolated between both association-centres .... Through such an interpolation, the somatic sensory sphere which mediates the consciousness of the body would become altogether of particular importance for the unity of mental function." . . . (pp. 82-83)

About the comparative importance of the association-centers only few completely certain experiences are so far available. In rodents (I have examined the domestic mouse and the hamster) these centers are completely absent. Sensory centers border immediately on one another so that - with few exceptions - the whole cortex consists of projection centers only. Correspondingly, only those association systems are found which run within the cortex or connect some projection centers with each other such as the cingulum, the fornix longus, the striae of Lancisi, etc. ..... In predatory carnivores the association-centers are relatively small. One should only compare the excitable frontal brain of the dog and lower monkeys with that of man! Only in higher apes do the associationcenters approach the same extent as the 
sensory-centers, and in man only do they surpass these centers. For this reason it would be a great mistake to expect to find the great outlines of the human association systems by, for example, study of the mouse brain. They can be studied with success in man only or possibly in the highest anthropoid apes. Likewise, conferring some physiological experiences in animal brains to the human brain may result in major errors - when, for example, following Munk, we should assume that the cerebral cortex consists essentially of sensory centers. Even if this may be correct for some experimental animals, it would not justify the transfer of these results to the human brain. Any reexamination of my new ideas about the organization of the human cortex .... must be undertaken in the human brain though not only by carmine staining of the adult normal brain, but by employing really exact methods . . . " (pp. 84-85).

\section{RECEPTION OF "GEHIRN AND SEELE"}

The best description of the impression Flechsig made with his publication on neurologists, physiologists and psychologists of many centers has been given by Ramón y Cajal (1911). He described it as an emotion of a magnitude comparable only with that accorded to the cellular pathology of Virchow and to the bacteriological investigations of Pasteur. However, "disenchantment followed soon the enthusiasm, both exaggerated" (quoted from the translation by von Bonin, 1960). Among Flechsig's critics we find Oscar Vogt (1901, 1903), Constantin v. Monakow (1911), J. Dejerine (1901) and Korbinian Brodmann (1909).

Vogt, Monakow and Cajal all criticized the sharp distinction he made between projection centers and association centers since most of the latter have reciprocal thalamic connections just as much as the former. Flechsig met this criticism in 1898 and again 1901 when he dropped the term 'association'; from that time he differentiated between primordial centers (fully myelinated at birth), intermediary centers (myelinated one month after birth) and terminal centers (starting myelination at about four months after birth). This more flexible division met the objections of most of his critics that his system was too rigid.

Oscar Vogt considered the difference between fibers within the projection centers and those of association were better explained by a difference in calibre than by intrinsic quality, but this criticism was rejected by Flechsig in all his subsequent publications. Vogt also drew attention to the superiority of cytoarchitectonic and myeloarchitectonic techniques considering them more reliable and more informative of the laminary architecture of the cortex. He had the full support of Brodmann.

Dejerine (1901) joined most of the other critics in denying Flechsig's contention that there were no projection tracts in associationcenters. Among others he mentioned Türk's temporo-pontine tract which he found degenerating after lesions confined to the second and third temporal convolution (see his case Neumann, pp. 145/6). Flechsig, however, rejected this criticism pointing out that this bundle arises from the first temporal convolution near the acoustic center. Dejerine's cases may be explained by the interruption of the tract in its downward course.

Cajal criticized Flechsig's contention that the hippocampus, as well as the subiculum and part of the gyrus fornicatus receive direct olfactory fibers. Cajal had shown convincingly that olfactory fibers of the first order end in what he named the sphenoid cortex, between the presubiculum and the rhinal fissure.

Monakow's criticism was directed against Flechsig's too rigid localization of cerebral cortex concerned with psychological function. In introducing the principle of "diaschisis" he foreshadowed the later 'holistic' principle of cerebral localization of Henry Head (1926) and Kurt Goldstein (1927). Schröder (1930) was right in pointing out that at the time of his death Flechsig's views on cerebral localization were largely out of date, though, in defence of Flechsig, he shared this error with many of his contemporaries.

As Cajal (1911) pointed out, Flechsig and Monakow had emphasized the existence of both phylogenetically old and more recent centers; "thus, their results could be reconciled. Flechsig was forced to change some of his views in his papers after 1896: the change of terminology has been mentioned above, but he also accepted that projections may arise from intermediary and terminal regions, although they were far less numerous than those in sensorymotor projection centers. The latter (both ascending and descending) had more intimate (and less interrupted) connexions with the periphery (sense organs in skin and muscles, anterior horn cells of the spinal cord) than those arising from later myelinating centers.

Despite these criticisms, it is remarkable, as von Bonin (1960, pp. Xv and $x v i)$ has pointed out, that Flechsig's myelogenetic method and its usage for the localization of cortical function has retained its place beside the cyto- and myelogenetic methods which the Vogts and Brodmann so much preferred and which have proved to be more popular than Flechsig's techniques. One explanation for the lack of support for Flechsig's method is that it can be used only in the brains of the newborn and in the first years of life. To all appearances, the method is not easy and the interpretation of its results requires considerable experience. Von Bonin was surprised to find that the cortical parcellation achieved by it had never been re-examined. One should not forget, however, that Flechsig and his early associates, and later Pfeifer (1921, 1936) and Klose (1920) were able correctly to identify the ascending auditory pathway in its course from the auditory nucleus to the medial geniculate body, its further progress into the anterior transversal (Heschl) convolution and the exact distribution of the auditory radiation within the cortical center. According to Flechsig (1908), the myelination of the auditory radiation and the acoustic center is, among sensory centers, the last to mature. Such results prove the value of the method. Moreover, in his later years, as Pfeifer (1930) told us, Flechsig continued indefatigably together with his associates to reexamine his cortical centers almost until his death.

Von Bonin probably knew Langworthy's publication of 1933 in which he related behavioral aspects of the foetus and of the newborn to the degree of myelination; but since this work was confined to early stages of development, von Bonin had apparently judged it not to be a reexamination of Flechsig's localization of the cerebral cortex. Two years after Bonin's statement Yakovlev (1962) began to publish his great work on "morphogenesis". It was followed by a further publication in 1967 by Yakovlev and Lecours. In both papers the authors praised Flechsig's pioneering and careful observations, but stressed that now these had to be incorporated into a wider concept which would also take into account the "tectonic" work of Kaes (1907) and the architectonic studies of Brodmann (1909), Economo and Koskinas (1925), of the Vogts (1919) and of Bailey and Bonin (1951). In his fig. I.12 (1962, p. 23) Yakovlev demonstrated that most of Flechsig's fields could, with only few 


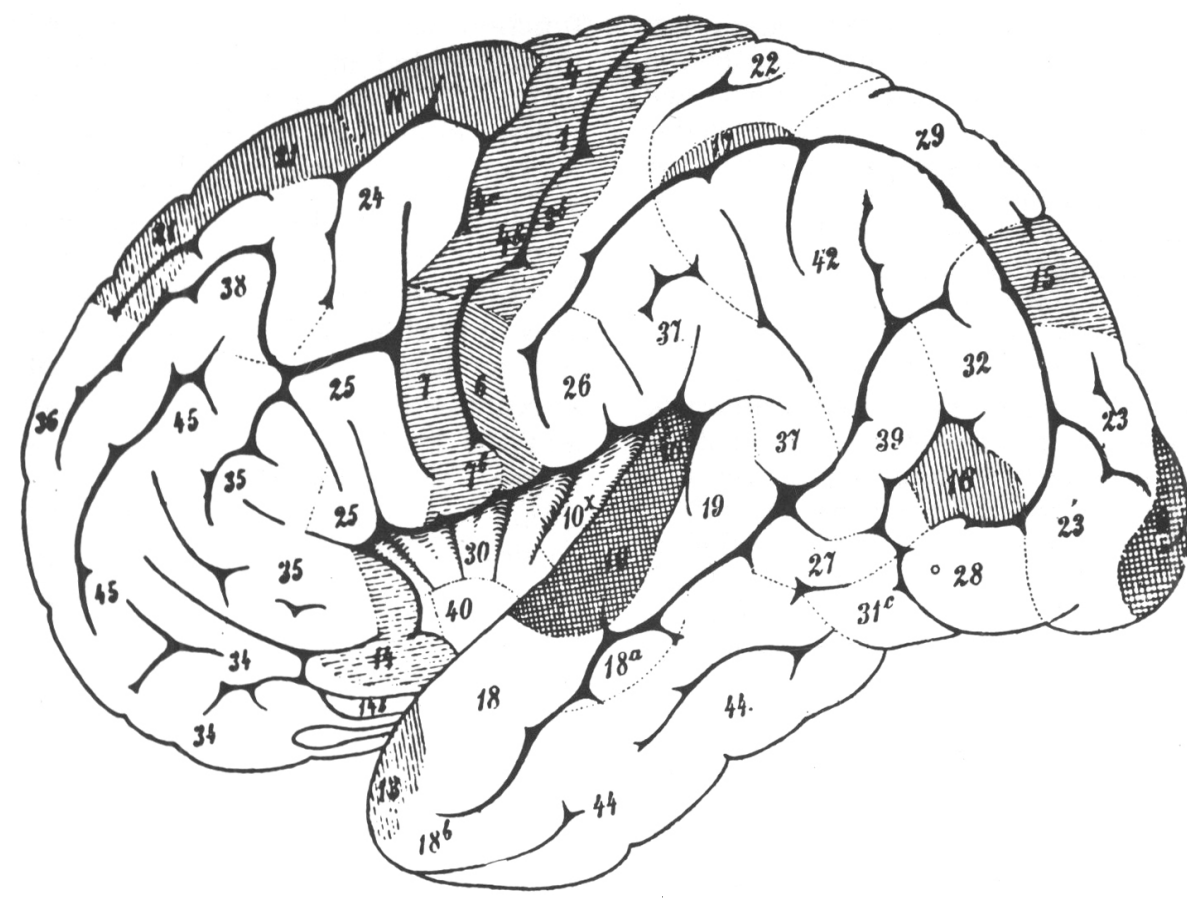

Figure 3 - (reproduced from fig. 1 of Flechsig, 1920, by courtesy of the Librarian, Rockefeller Medical Library, Institute of Neurology, London). Explanation in text.

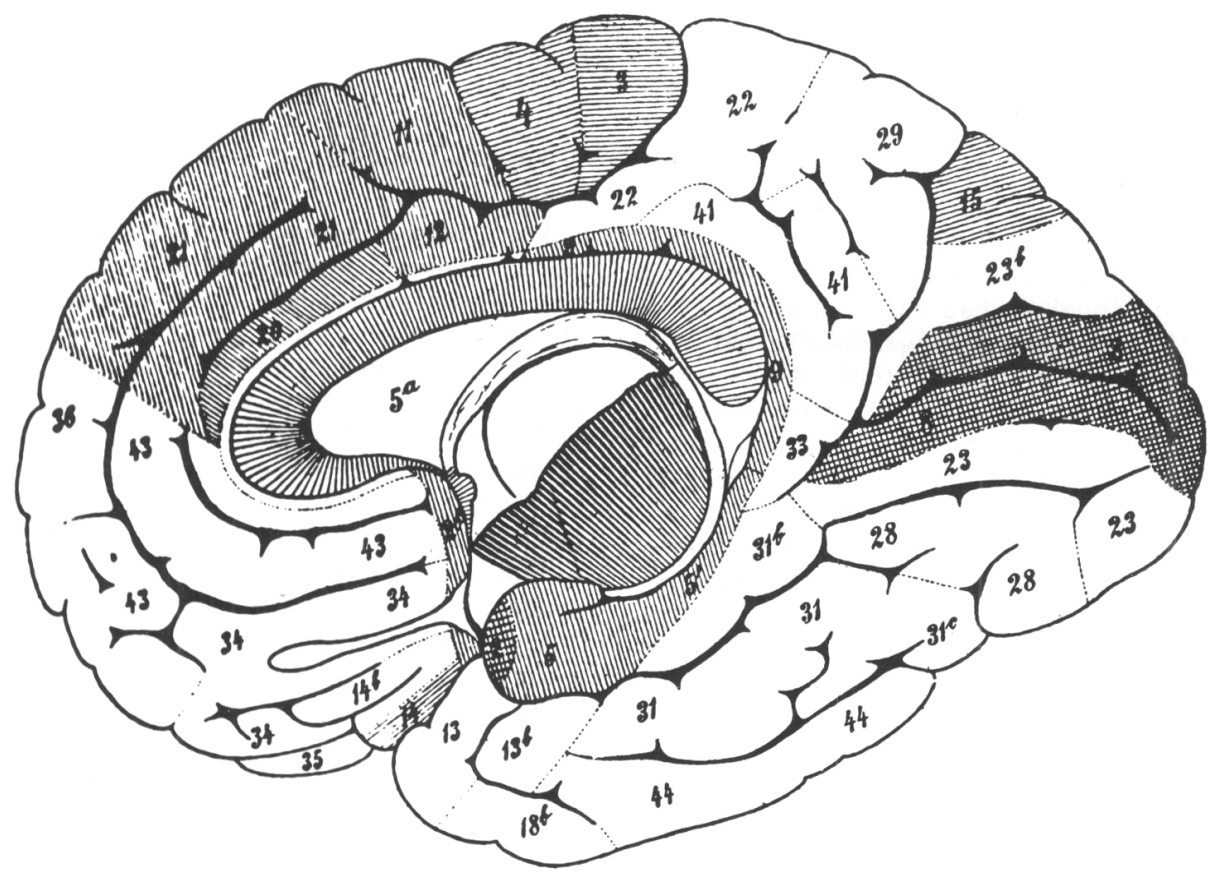

Figure 4 - (reproduced from fig. 2 of Flechsig, 1920, by courtesy of the Librarian, Rockefeller Medical Library, Institute of Neurology, London). Explanation in text. exceptions (fields $15-17$, and $40-41$ ), well be correlated with the cytoarchitectonic studies mentioned above. Flechsig's fields also fitted in with the broad divisions such as Brodmann's homogenetic versus heterogenetic cortex, the Vogts' isocortex versus allocortex, and with the palaeocortex and archicortex of Filimonofff $(1929,1947)$. (The latter terms had been introduced by Ariens Kappers (1909), were replaced by the Vogts' uniform allocortex, but resurrected by Filimonoff. The peripalaeo- and periarchitectoral areas of Filimonoff correspond to some extent at least to Rose's (1927) mesocortex and to what is commonly referred to as the limbic lobe.)

Yakovlev and Lecours insisted that the "cycles of myelination" should be followed up over far longer periods than Flechsig had done. In their fig. 1, for example, it can be seen that in the association-centers, myelination begins at the fourth extrauterine month (as Flechsig had correctly described), but it continued to develop far into the third decade of life. A glance at Flechsig's (1920) tables shows that in his terminal zones one finds only the incoming perpendicular fibers stained; there is virtually no neuropil which appears only in later stages. The outer Kaes-Bechterew stripe is the latest to appear.

In his introductory remarks on Flechsig, von Bonin found it interesting to notice how modern "Flechsig is in his analysis of the frontal lobes" and - one may add - of the posterior terminal center. $\mathrm{He}$ also considered that Flechsig did not fully grasp the problems, but nevertheless he was the first to have any inkling of the true state of affairs. As Pribram (1974, p. 187) expressed it, research on functional cortical organization in general, and the association centers in particular, has been expanding at an "unprecedented pace during the last few decades" (although Flechsig's name is now seldom mentioned).

It is with these rapid advances and how they relate to the results and conclusions of Flechsig, that the following sections of this paper will be concerned. 